\title{
Pravastatin reduces radiation-induced damage in normal tissues
}

\author{
HIROSHI DOI $^{1}$, SEIJI MATSUMOTO ${ }^{2}$, SOICHI ODAWARA ${ }^{1}$, \\ TOSHIYUKI SHIKATA ${ }^{3}$, KAZUHIRO KITAJIMA ${ }^{1}$, MASAO TANOOKA ${ }^{4}$, YASUHIRO TAKADA ${ }^{1}$, \\ TOHRU TSUJIMURA ${ }^{5}$, NORIHIKO KAMIKONYA ${ }^{1}$ and SHOZO HIROTA ${ }^{1}$
}

\author{
Departments of ${ }^{1}$ Radiology and ${ }^{2}$ Thoracic Surgery, Hyogo College of Medicine, Nishinomiya, Hyogo 663-8501; \\ ${ }^{3}$ Department of Pharmacy, Hyogo College of Medicine Sasayama Medical Center, Sasayama, Hyogo 669-2321; \\ ${ }^{4}$ Department of Radiological Technology, Hyogo College of Medicine College Hospital, Nishinomiya; \\ ${ }^{5}$ Department of Pathology, Hyogo College of Medicine, Nishinomiya, Hyogo 663-8501, Japan
}

Received December 20, 2015; Accepted December 23, 2016

DOI: $10.3892 /$ etm.2017.4192

\begin{abstract}
Pravastatin is an inhibitor of 3-hydroxy-3-methylglutaryl-coenzyme A reductase that has been reported to have therapeutic applications in a range of inflammatory conditions. The aim of the present study was to assess the radioprotective effects of pravastatin in an experimental animal model. Mice were divided into two groups: The control group received ionizing radiation with no prior medication, while the pravastatin group received pravastatin prior to ionizing radiation. Pravastatin was administered orally at $30 \mathrm{mg} / \mathrm{kg}$ body weight in drinking water at 24 and $4 \mathrm{~h}$ before irradiation. Intestinal crypt epithelial cell survival and the incidence of apoptosis in the intestine and lung were measured post-irradiation. The effect of pravastatin on intestinal DNA damage was determined by immunohistochemistry. Finally, the effect of pravastatin on tumor response to radiotherapy was examined in a mouse mesothelioma xenograft model. Pravastatin increased the number of viable intestinal crypts and this effect was statistically significant in the ileum $(\mathrm{P}<0.0001)$. The pravastatin group showed significantly lower apoptotic indices in all examined parts of the intestine $(\mathrm{P}<0.0001)$ and tended to show reduced apoptosis in the lung. Pravastatin reduced the intestinal expression of ataxia-telangiectasia mutated and gamma-H2AX after irradiation. No apparent pravastatin-related differences were observed in the response of xenograft tumors to irradiation. In conclusion, pravastatin had radioprotective effects on the intestine and lung and reduced radiation-induced DNA double-strand breaks. Pravastatin may increase the therapeutic index of radiotherapy.
\end{abstract}

Correspondence to: Dr Hiroshi Doi, Department of Radiology, Hyogo College of Medicine, 1-1 Mukogawa-cho, Nishinomiya, Hyogo 663-8501, Japan

E-mail: h-doi@hyo-med.ac.jp

Key words: pravastatin, radioprotectant, radiotherapy, 3-hyrdoxyl-3-methyl-glutaryl-conenzyme A reductase, statin, DNA double-strand breaks, DNA damage response, mesothelioma

\section{Introduction}

Radiotherapy plays an important role in cancer treatment. Radiation-induced gastrointestinal disorders are the most common adverse events associated with the treatment of malignancies affecting the abdomen and pelvis (1). These disorders often reduce the patient's quality of life during treatment and sometimes limit the dose of radiotherapy that can be used to treat abdominal and pelvic tumors (2). Amifostine has been recommended for preventing severe radiation-induced toxicities and is the only radioprotectant that has been approved by the US Food and Drug Administration (3). However, the daily use of amifostine is limited because of its hematological and gastrointestinal toxicity (4).

Pravastatin, an inhibitor of 3-hydroxy-3-methyl-glutarylconenzyme A (HMG-CoA) reductase, is widely used to treat hypercholesterolemia and has been reported to have a therapeutic applicability in a range of inflammatory conditions $(5,6)$. Statins have previously been reported to have beneficial effects on radiation-induced toxicities, and numerous studies have demonstrated the anti-inflammatory effects of pravastatin following radiation exposure (7-15). Previous clinical data has shown that the use of statins reduces acute gastrointestinal symptoms following radical pelvic radiotherapy (15). Lovastatin has been reported to accelerate DNA repair after radiation exposure $(11,12)$. The radioprotective effects of statins are due to the inhibition of several inflammatory kinases, including Rho and Rho-associated protein kinases $(7,8,13)$. However, the mechanism of the radio protective effect of statins remains unclear. In addition, only a few experimental studies have reported the radioprotective effects of pravastatin and these remain to be completely elucidated (7-10).

The aim of the present study was to assess the radioprotective effects of pravastatin in normal tissues using an animal model.

\section{Materials and methods}

Animals and reagents. Male C57BL/6 J mice, aged 7-8 weeks and weighing 20-28 g, were obtained from Charles River Laboratories Japan, Inc. (Yokohama, Japan) and used in the 
present study. All mice were acclimated for 7 days. They were housed 3 to 5 per cage (temperature, $23 \pm 2^{\circ} \mathrm{C}$; humidity; $55 \pm 10 \%$; 12-h light/dark cycle) and fed with a laboratory rodent pellet formula and tap water ad libitum. All of the animal experiments described herein were approved by the Hyogo College of Medicine (Nishinomiya, Japan) Institutional Animal Care and Use Committee (approval numbers: 13-047 and 14-065). Pravastatin sodium salt hydrate was obtained from Sigma-Aldrich Japan K.K. (Tokyo, Japan). Pravastatin was orally administered at $30 \mathrm{mg} / \mathrm{kg}$ body weight in drinking water 24 and $4 \mathrm{~h}$ prior to irradiation. The same volume of water with no drugs was administered to the control group. Mice were irradiated at a dose of $\sim 200 \mathrm{cGy} / \mathrm{min}$ using a $150 \mathrm{kVp}$ X-ray unit, Hitachi MBR-1520 (20 mA, 150 kV; Hitachi Ltd., Tokyo, Japan). For dosimetry, a probe connected to an electrometer system was placed close to the target site. Peritoneal injection of sodium pentobarbital (Somnopentyl, Kyoritsu Seiyaku, Tokyo, Japan) at $\sim 45 \mathrm{mg} / \mathrm{kg}$ body weight was used throughout the experiment for anesthesia.

Intestinal crypt stem cell survival assay. The detailed procedure for analysis of intestinal crypt cell survival following irradiation has been described previously (16). Each treatment group included four mice. A total body irradiation of $15 \mathrm{~Gy}$ was delivered in a single fraction and the mice were sacrificed 3.5 days after irradiation by peritoneal injection of sodium pentobarbital (>200 mg/kg body weight). The duodenum, jejunum, and ileum were removed, fixed and stained with hematoxylin and eosin (H\&E). Surviving crypts that had $\geq 10$ cells in each cross-section were counted using light microscopy. In addition, the numbers of surviving crypts in eight intestinal slices from each part of the intestine were counted.

Analysis of apoptosis in the intestine. The procedure for the analysis of apoptosis in normal intestine following irradiation has been described previously $(17,18)$. Each treatment group included four mice. A total body irradiation of 2 Gy was delivered in a single fraction. At $4 \mathrm{~h}$ after irradiation, the duodenum, jejunum and ileum were removed, fixed and stained with H\&E. Apoptotic cells were defined as epithelial cells with apoptotic fragments in the H\&E-stained sections. The numbers of apoptotic cells were quantified by counting the number of apoptotic cells in each crypt (16 crypts per mouse). In addition, the proportion of apoptotic cells in each crypt was expressed as the apoptotic index.

Immunohistochemistry (IHC). The effects of pravastatin on radiation-induced DNA double-strand breaks were investigated using IHC to detect ataxia-telangiectasia mutated (ATM) and gamma-H2AX. Formalin-fixed and paraffin-embedded ileum tissue sections were prepared as described above for the analysis of apoptosis, autoclaved and then placed in $1 \%$ $\mathrm{H}_{2} \mathrm{O}_{2}$. The slides were incubated with a rabbit monoclonal antibody raised against ATM $(1.96 \mu \mathrm{g} / \mathrm{ml}$; ab81292; Abcam, Cambridge, UK) or a rabbit polyclonal antibody raised against gamma-H2AX $(0.005 \mathrm{mg} / \mathrm{ml}$; ab11174, Abcam) overnight at $4^{\circ} \mathrm{C}$. Following washing, the slides were incubated with the secondary antibody, a biotinylated anti-mouse immunoglobulin and horseradish-conjugated streptavidin (LSAB2; K0609; Dako Japan Co., Ltd., Tokyo, Japan) for ATM or a horseradish peroxidase-conjugated anti-rabbit immunoglobulin (Histofine $^{\circledR}$ Simple Stain ${ }^{\mathrm{M}}$ Mouse MAX PO (Rabbit); 414341, Nichirei Biosciences, Inc., Tokyo, Japan) for gamma-H2AX, stained using a diaminobenzidine kit (045-22833; Wako Pure Chemical Industries, Ltd., Osaka, Japan), then counterstained with hematoxylin. The number of ATM-positive cells was counted in 16 randomly selected intestinal crypts in each mouse. In addition, the number of gamma-H2AX-positive cells was counted in 25 villus cells from five randomly selected villi in each mouse.

Analysis of apoptosis in the lung. The detailed procedure used for this analysis has been described previously (19). Each treatment group included four mice. A total body irradiation of $5 \mathrm{~Gy}$ was delivered in a single fraction and the mice were sacrificed by peritoneal injection of sodium pentobarbital $>200 \mathrm{mg} / \mathrm{kg}$ body weight $6 \mathrm{~h}$ after irradiation. The lungs were removed, fixed in $10 \%$ neutral buffered formalin solution, then stained with H\&E. DNA fragmentation was examined histologically using terminal deoxynucleotidyl transferase (TdT)-mediated d-UTP nick end labeling (TUNEL). The ApoTag Kit (S7100; Merck Millipore, Billerica, MA, USA) was used for TUNEL labeling. Paraffin sections (thickness, $\sim 3 \mu \mathrm{m}$ ) were deparaffinized and rehydrated through graded ethanol up to distilled water. Tissues were digested using proteinase K (164-14004; Wako Pure Chemical Industries, Ltd.), placed in $2 \% \mathrm{H}_{2} \mathrm{O}_{2}$, then rinsed with phosphate-buffered saline (PBS, S3024; Dako Japan Co., Ltd.). Sections were then coated with TdT enzyme and incubated at $37^{\circ} \mathrm{C}$ for $30 \mathrm{~min}$. After several washes in a stop buffer (S7100; EMD Millipore, Billerica, MA, USA) at $37^{\circ} \mathrm{C}$ for $30 \mathrm{~min}$, an anti-digoxigenin-peroxidase antibody (S7100; EMD Millipore) was applied to the sections. Following subsequent washes with PBS and staining with DAB staining solution (045-22833; Wako Pure Chemical Industries, Ltd.), the lung sections were counterstained with hematoxylin. For quantification of TUNEL-positive cells, tissue sections were analyzed at X40 magnification and TUNEL positive cells were counted. Five lobes were examined in each mouse and four different fields were randomly analyzed per lobe. The average of all evaluated fields in each lobe was defined as its apoptotic score.

Analysis of the effect of pravastatin on tumor growth rate. An xenograft tumor model was established as described previously (20). Human mesothelioma cells (NCI-H226) were obtained from American Type Culture Collection (Manassas, VA, USA), were suspended in $0.10 \mathrm{ml}$ RPMI-1640 solution (Sigma-Aldrich Japan K.K.) and injected $\left(5 \times 10^{6}\right.$ cells per mouse) subcutaneously into the lower back of female nude

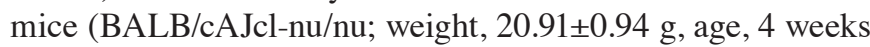
old) obtained from CLEA Japan, Inc. (Tokyo, Japan). All mice were acclimated for 7 days. They were housed 3 per cage (temperature, $23 \pm 2{ }^{\circ} \mathrm{C}$; humidity; $55 \pm 10 \%$; 12-h light/dark cycle) and fed with a laboratory rodent pellet formula and tap water ad libitum. Mice were divided into four groups as follows: Three mice received no pravastatin and sham-irradiation; three mice received pravastatin and sham-irradiation; six mice were irradiated without pravastatin and six mice were irradiated after receiving pravastatin. Treatments were started when the xenograft tumors reached approximately $100 \mathrm{~mm}^{3}$ 
A

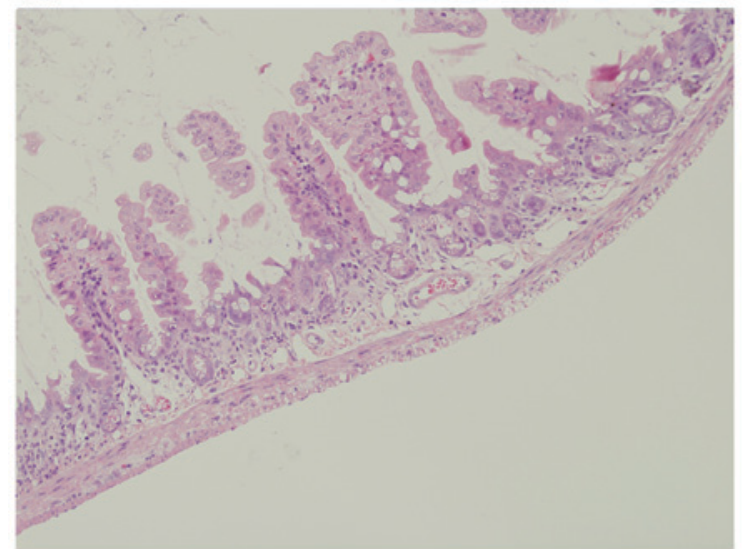

B

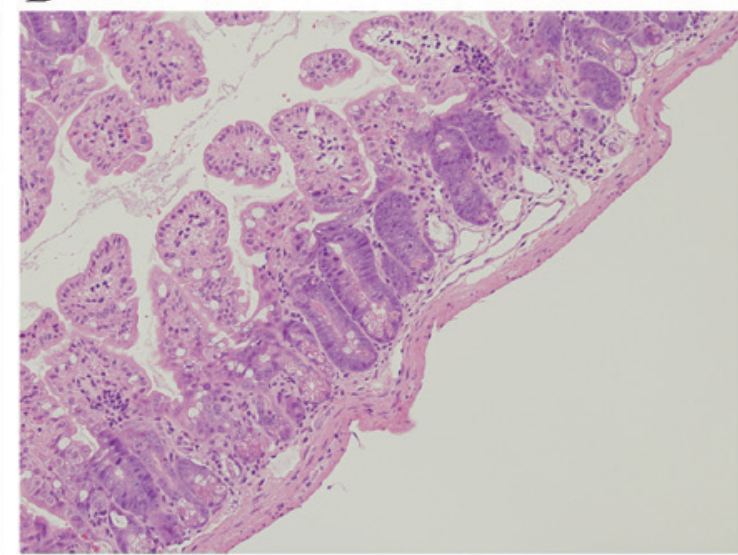

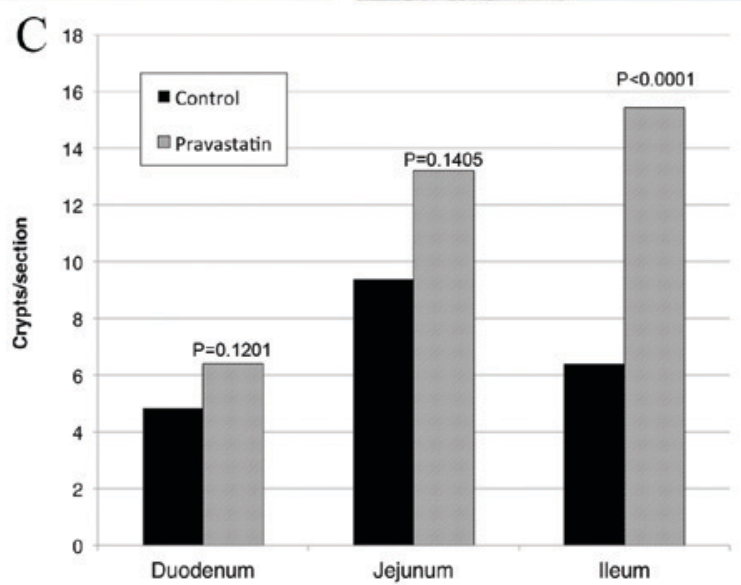

Figure 1. Pravastatin protected intestinal crypt stem cells (hematoxylin and eosin staining; original magnification, x40). (A) Jejunum tissue from a control mouse that was irradiated with no drug administration. Most intestinal crypts were destroyed and lost their shape. (B) Jejunum tissue from a mouse that received pravastatin 24 and $4 \mathrm{~h}$ prior to irradiation. More viable crypts were present, as compared with the control group. (C) Pravastatin administration increased the number of viable intestinal crypts in all of the assessed intestinal regions. This difference was statistically significant in the ileum (P<0.0001).

in volume, as calculated by $0.5 \mathrm{x}$ length $\mathrm{x}$ width ${ }^{2}$. For irradiation, the tumor-bearing mice were anesthetized by peritoneal injection of sodium pentobarbital ( $45 \mathrm{mg} / \mathrm{kg}$ body weight) and placed in individual lead boxes with the tumor protruding through a cutout window at the rear of each box. Radiation was delivered at a dose of $8 \mathrm{~Gy}$ in a single fraction. The tumor lengths and widths were measured with calipers before treatment, and three times per week thereafter. The tumor volume was normalized against the starting volume.

Statistical analysis. The data are expressed as the mean with standard deviations in parentheses, unless otherwise indicated. Data were analyzed using a two-tailed Fisher's test or a Mann-Whitney test. All analyses were performed using GraphPad Prism version 6.0b (GraphPad Software, Inc., San Diego, CA, USA) and $\mathrm{P}<0.05$ was considered to indicate a statistically significant difference.

\section{Results}

Effect of pravastatin on intestinal crypt cell survival. Radiation exposure reduced the survival of the crypts (Fig. 1A). The pravastatin group exhibited an increased number of viable crypts in the intestine (Fig. 1B). The number of viable crypts in the duodenum, jejunum and ileum was $4.84 \pm 5.90,9.38 \pm 10.31$ and $6.41 \pm 5.31$ in the control group, and $6.41 \pm 7.84,13.22 \pm 13.02$ and $15.44 \pm 8.22$ in the pravastatin group, respectively (Fig. 1C). This pravastatin-induced increase in the number of viable crypts was statistically significant in the ileum $(\mathrm{P}<0.0001)$.

Effect of pravastatin on apoptosis in the intestine. Radiation exposure induced apoptosis in the intestinal crypts (Fig. 2A). The pravastatin group exhibited a reduced number of apoptotic cells in the intestine (Fig. 2B). The apoptotic index in the duodenum, jejunum and ileum was $0.19 \pm 0.09,0.23 \pm 0.10$ and $0.28 \pm 0.10$ in the control group, and $0.08 \pm 0.06,0.10 \pm 0.07$ and $0.10 \pm 0.07$ in the pravastatin group, respectively (Fig. 2C). The pravastatin group showed significantly less apoptosis in all examined parts of the intestine $(\mathrm{P}<0.0001)$.

Effect of pravastatin on radiation-induced DNA double-strand breaks. IHC analyses found that the pravastatin group showed fewer ATM- and gamma-H2AX-positive cells than the control group (Fig. 3A and B). To assess the effect of pravastatin on ATM expression in normal intestine, mice were sacrificed $4 \mathrm{~h}$ after two doses of pravastatin or drinking water and ATM-positive cells were evaluated. The proportion of ATM-positive cells was $0.83 \pm 0.13$ and $0.69 \pm 0.14$ in the control and pravastatin groups, respectively $(\mathrm{P}<0.0001$; Fig. $3 \mathrm{C})$. The proportion of gamma-H2AX-positive was $0.91 \pm 0.08$ and 


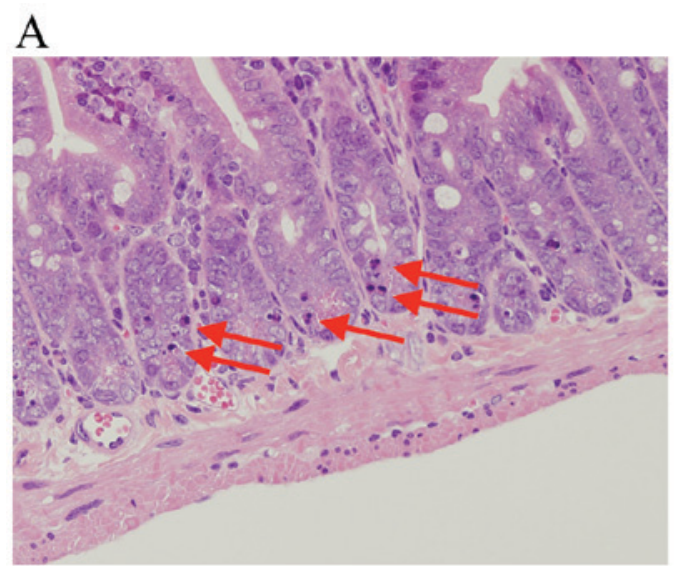

B

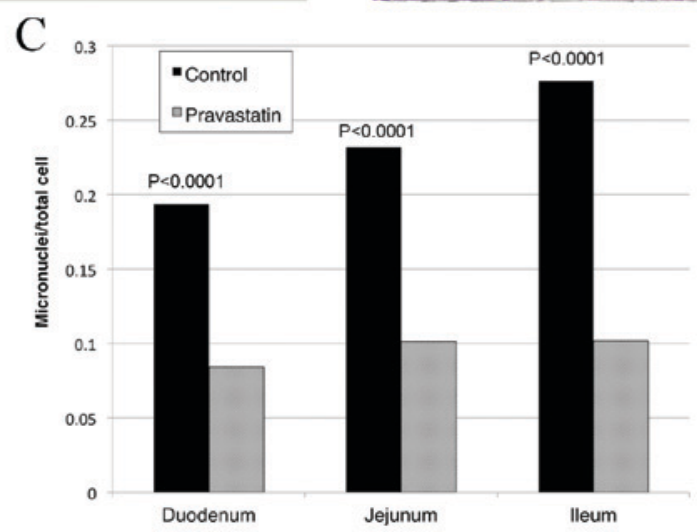

Figure 2. Pravastatin reduced intestinal cell death (hematoxylin and eosin staining; original magnification, $\mathrm{x} 40$ ). (A) Duodenum tissue from a control mouse that was irradiated with no drug administration. Dying cells with micronuclei were observed in the intestine (indicated with arrows). (B) Duodenum tissue from a mouse that was treated with pravastatin 24 and $4 \mathrm{~h}$ prior to irradiation showed fewer dying cells with micronuclei (arrow). (C) Calculation of the incidence of apoptotic cells in crypts showed that pravastatin administration significantly reduced cell death in all of the assessed parts of the intestine $(\mathrm{P}<0.0001)$.

$0.82 \pm 0.10$ in the control and pravastatin groups, respectively $(\mathrm{P}=0.0079$; Fig. 3D). No significant difference was observed in the incidence of ATM-positive cells following pravastatin administration (Fig. 3E). However, no significant improvement was observed in radiation-induced acute gastrointestinal syndrome using a murine survival assay (21) after total abdominal irradiation of $20 \mathrm{~Gy}$ in a single fraction (data not shown).

Effect of pravastatin on apoptosis in the lung. H\&E stating revealed no apparent differences between the lungs of irradiated mice, as compared with un-irradiated mice (Fig. 4A). TUNEL staining indicated apoptotic cells in the alveolus (Fig. 4B and C). The number of TUNEL-positive cells per lobe was $4.26 \pm 1.43$ in the control group and $3.36 \pm 1.89$ in the pravastatin group $(\mathrm{P}=0.060)$. This difference was not statistically significant (Fig. 4D).

Effect of pravastatin on tumor growth rate after irradiation. Pravastatin treatment had no negative impact on the growth rates of xenograft tumors after irradiation (Fig. 5).

\section{Discussion}

Although radiotherapy provides a highly effective treatment option for malignancies, the resulting gastrointestinal and lung toxicities can be life-threatening and there are no well-established treatments for these. Statins are HMG-CoA reductase inhibitors that are widely used to treat hypercholesterolemia; their potential radioprotective effects have been discussed in a limited number of preclinical and clinical studies (5-15). Clinical studies have reported that pravastatin has anti-inflammatory effects and is a safe HMG-CoA reductase inhibitor that is water soluble (5). However, the use of pravastatin to reduce radiation-induced damage to normal tissue has not been investigated thoroughly, despite its promise for use as a radioprotectant (7-10).

Haydont et al reported that pravastatin suppressed late radiation-induced submucosal fibrosis in the intestine, although no differences were observed in acute intestinal changes after radiation exposure $(8,9)$. However, the present study identified reproducible radioprotective effects of pravastatin on acute radiation-induced injury in the intestine and the lung. Late intestinal complications are common following radiotherapy for abdominal and pelvic malignancies and these can substantially reduce the patient's quality of life (2). The mechanism underlying late radiation damage involves chronic inflammation, leading to fibrogenesis and angiopathy $(22,23)$. The present study focused on the acute effects of radiation exposure, in order to clarify the radioprotective effects of pravastatin accurately. In addition, the classical radiobiological view of radiation-induced tissue injury as the direct consequence of DNA damage and cell death in target cells means that the severity of tissue damage is directly related to cell depletion during this acute 
A

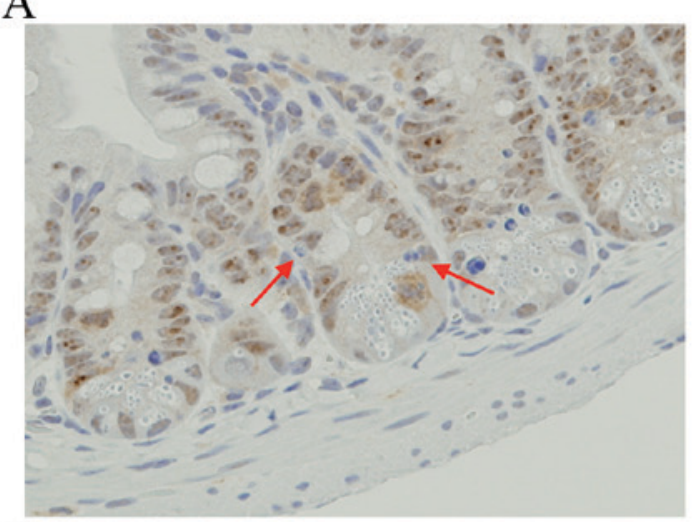

$\mathrm{C}$

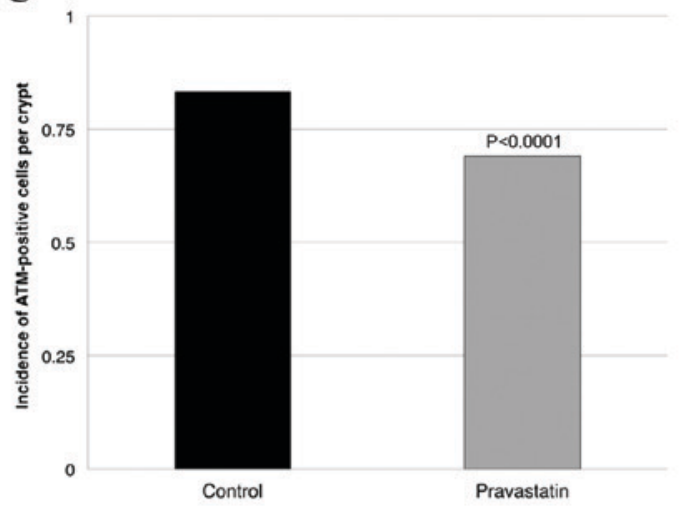

B
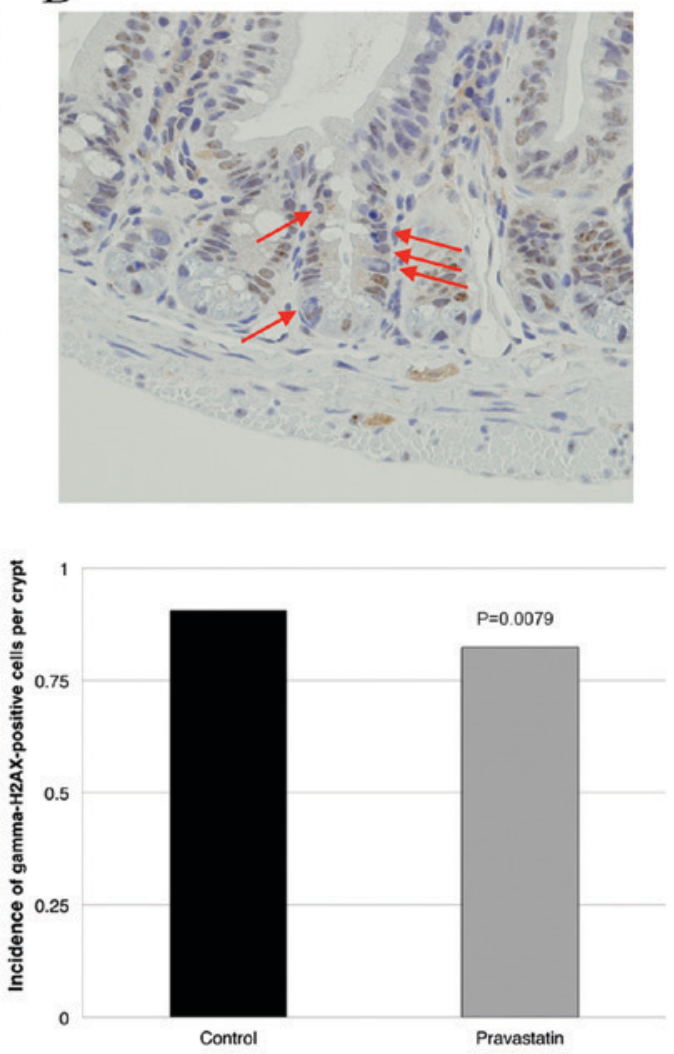

$\mathrm{D}$

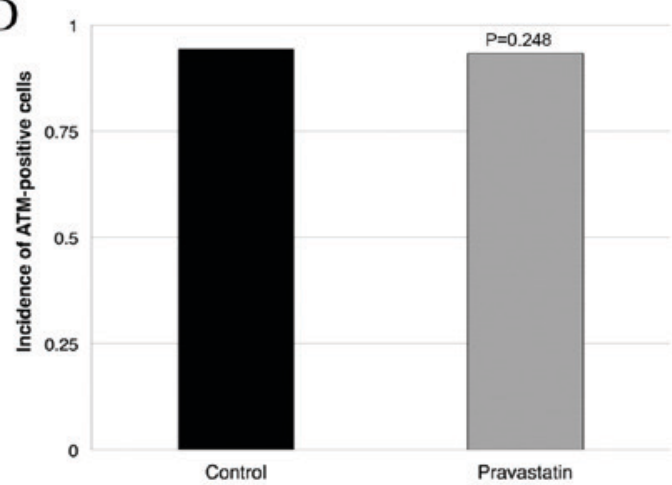

Figure 3. Pravastatin reduced DNA double-strand breaks following radiation exposure. Immunohistochemistry was performed in the ileum of mice exposed to radiation, with (pravastatin group) or without (control group) administration of pravastatin 24 and $4 \mathrm{~h}$ previously (original magnification, $\mathrm{x} 40$ ). (A) Ileum tissue from a control mouse that was irradiated with no drug administration. ATM-negative cells in the villi of the control group are indicated with arrows. (B) Ileum tissue from a mouse that received pravastatin. There were a greater number of ATM-negative cells in the pravastatin group than the control group. (C) The pravastatin group showed significantly fewer ATM-positive cells in the jejunum compared with the control group (P<0.0001). (D) The pravastatin group showed fewer gamma-H2AX-positive cells in the jejunum compared with the control ( $\mathrm{P}=0.0079)$. (E) The administration of pravastatin (in the absence of irradiation) did not significantly modify ATM expression in the intestine. ATM, ataxia-telangiectasia mutated.

phase. Moreover, acute injury has been primarily attributed to apoptosis of epithelial stem cells (24).

The effect of pravastatin on radiation-induced DNA damage is less understood. Mahmoudi et al and Nübel et al report that lovastatin accelerates DNA repair $(11,12)$. However, Mahmoudi et al also reports that neither the initial nor residual levels of DNA damage are affected by this statin (11). Data from the current study suggested that pravastatin suppressed radiation-induced DNA double-strand breaks and cell death in the normal intestine. These results indicate the potential of pravastatin as an effective radioprotectant, although further investigations should be performed to characterize this.
Gomez et al reported that the $\geq$ grade 3 toxicity rates are $12 \%$ in the lung and $16 \%$ in the gastrointestinal tract following intensity modulated radiation therapy after extrapleural pneumonectomy for malignant pleural mesothelioma (25). Therefore, a mesothelioma cell line was used in this study to assess the potential use of pravastatin to reduce radiation-induced pneumonitis and colitis in future clinical trials. In addition, Haydont et al reported that pravastatin does not reduce the anticancer effects of radiotherapy in experimental models using colorectal, cervical and prostate carcinoma cell lines (9). Consistent with previous findings, the present study found no negative effects of pravastatin on the response of human mesothelioma xenograft tumors to radiotherapy $(9,26)$. 
A

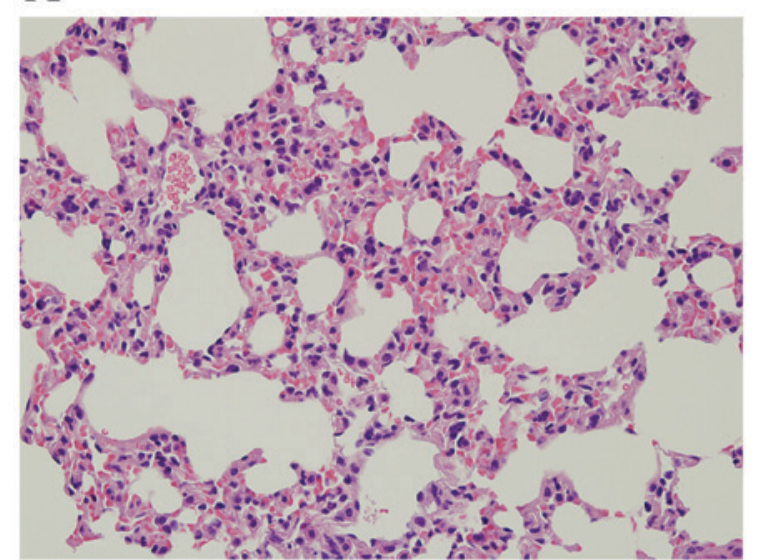

$\mathrm{C}$

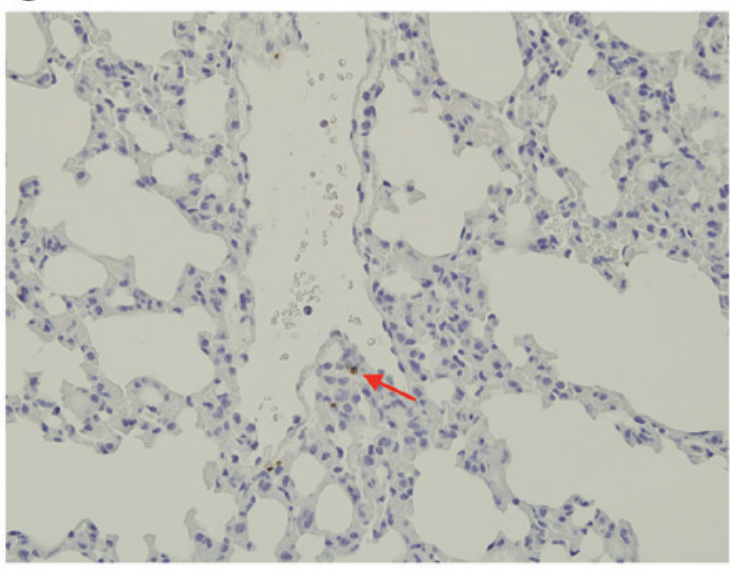

B

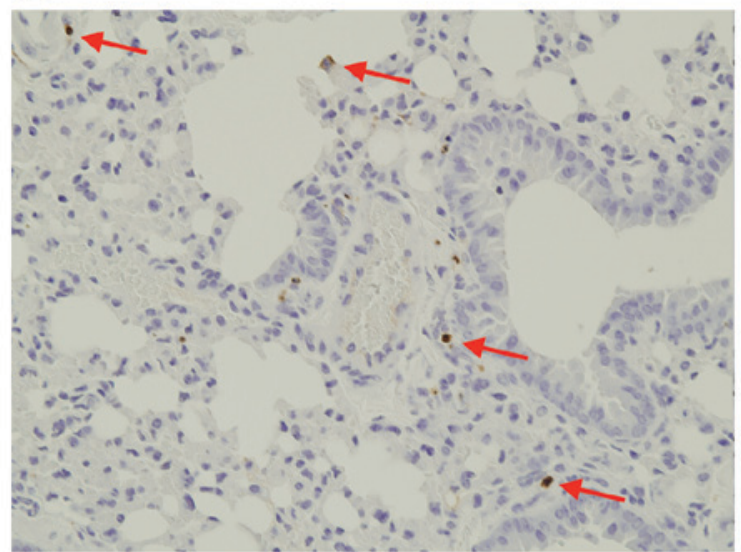

$\mathrm{D}$

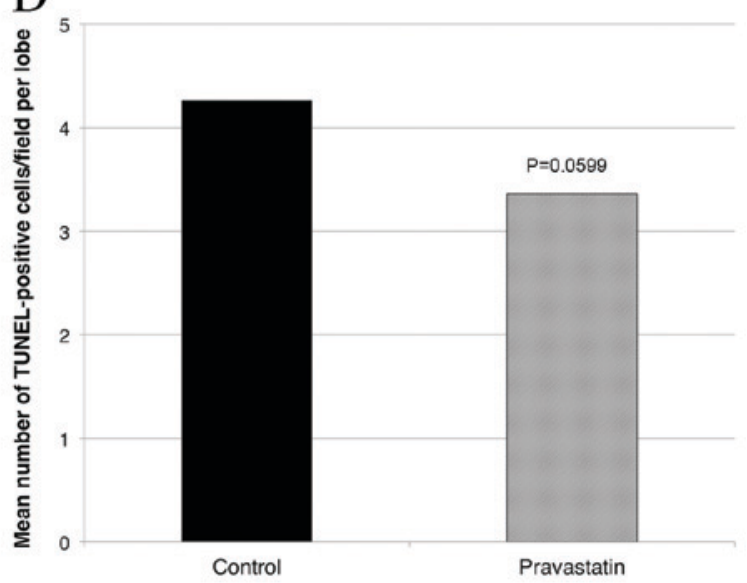

Figure 4. Effect of pravastatin on apoptosis in the lung. (A) Hematoxylin and eosin staining revealed no apparent differences between the lungs of irradiated mice (original magnification, $\mathrm{x} 40$ ), as compared with untreated mice (not shown). Apoptotic cells were detected in (B) the control group and (C) the pravastatin group using TUNEL staining in the alveolus (apoptotic cells are indicated with arrows; original magnification, x40). Fewer TUNEL positive cells were observed in the pravastatin group than the control group. (D) Pravastatin administration tended to reduce apoptosis in normal lung tissue, although this difference was not statistically significant. TUNEL, terminal deoxynucleotidyl transferase-mediated d-UTP nick end labeling.

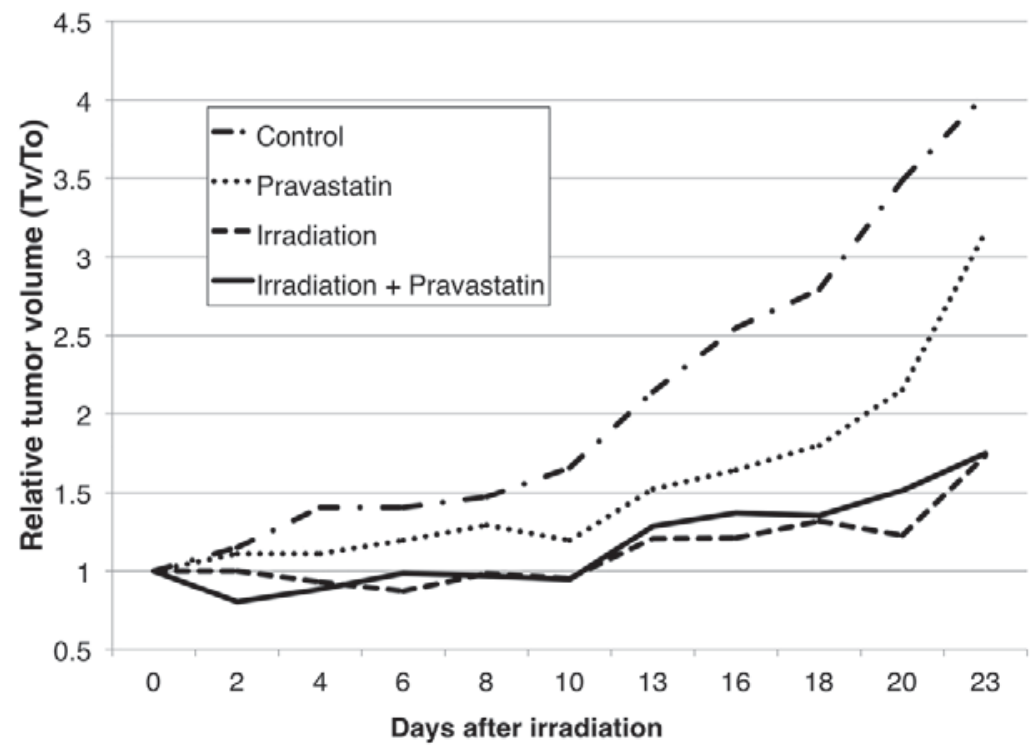

Figure 5. Pravastatin has no negative effect on the efficacy of radiotherapy in xenograft tumors. Changes in xenograft tumor volumes after irradiation are showed. Mice with subcutaneous xenograft tumors were treated with pravastatin and irradiation. Three mice received sham-irradiation with no administration of pravastatin; three mice received sham-irradiation with administration of pravastatin; six received irradiation alone with no administration of pravastatin and six received irradiation and pravastatin administration. No significant differences were observed between the groups with irradiation alone and irradiation with pravastatin $(\mathrm{P}=0.855)$, or between the groups with sham-irradiation alone and sham-irradiation with pravastatin $(\mathrm{P}=0.700)$. $\mathrm{T}_{\mathrm{v}}$, tumor volume; $\mathrm{T}_{0}$, tumor volume at day 0 . 
Therefore, there was no evidence that pravastatin negatively affected tumor treatment in these preclinical data.

Notably, pravastatin administration appeared to delay tumor growth in vivo. Because the main aim of the present study was to assess the potential negative effect of pravastatin on tumor response to radiotherapy, only a small number of animals were treated with pravastatin alone (sham-irradiated). Statins have been reported to have anti-tumor effects and some clinical data have supported their potential use against tumors (26-32). However, there has only been one randomized clinical trial studying this, which showed that the addition of pravastatin did not improve outcomes in patients with advanced gastric cancer (32). Therefore, the anti-tumor effect of pravastatin alone and the mechanism of this effect in relation to interstitial tumors (such as mesothelioma) should be investigated prior to clinical trials.

Previous reports have shown that the radioprotective effects of statins are due to the inhibition of several inflammatory kinases, including Rho and Rho-associated protein kinases, which regulate pro-inflammatory and pro-fibrotic stress responses, respectively $(7,8,13)$. In the present study, pravastatin reduced radiation-induced cell death and the expression of ATM and gamma-H2AX; these are related to the DNA damage responses following radiation exposure (33). In addition, the present study did not identify any pravastatin-induced modulation of ATM that caused cell cycle arrest. These data provide pre-clinical evidence for pravastatin-mediated protection from DNA damage caused by irradiation.

The present results indicated that pravastatin administration reduced radiation-induced cell death in normal lung tissue. The stronger radioprotective efficacy of pravastatin in the intestine compared with the lung might be explained by the fact that pravastatin uptake is mediated by bile acids and occurs specifically in the liver and ileum (34). Pravastatin is administered orally and has a good safety profile due to its water solubility and bile acid elimination pathway. It is widely accepted in clinical practice as a treatment for hypercholesterolemia and reportedly has a good safety profile, although it may be associated with mild and transient reactions $(5,35)$. It is therefore a strong candidate for investigation in clinical trials at the commonly used dosage.

Data from the current study suggest that a hydrophilic statin, pravastatin, can provide protection from radiotherapy-related toxicity in cancer patients, with no negative effects on the tumor response to radiotherapy. Further mechanistic pre-clinical and clinical studies should be conducted to determine the efficacy of pravastatin and to explore its potential for clinical application.

The present study has several limitations. Firstly, a relatively small number of animals were used. Secondly, pravastatin was shown to reduce radiation-induced apoptosis in the normal lung; however, no significant differences were detected. Thirdly, in this study, the lung was examined at a single time point after irradiation, based on a previous report (19). However, as pravastatin is water soluble, the metabolic pathway of pravastatin may affect the results. Therefore, it may be necessary to confirm our results in a study that includes a larger number of animals with multiple time points and various radiation doses. Finally, with regard to mechanistic experiments, IHC was used to identify the radioprotective effect of pravastatin through the reduction of DNA double-strand breaks. The replication of these findings in a subsequent study based on the findings of the present study, and a clinical study are required. In particular, upper stream of DNA damage responses following radiation exposure including reactive oxygen species and the affect of pravastatin on cell cycle remain unclear. We therefore suggest that further preclinical studies with different approaches may be required in order to fully elucidate the potential use of pravastatin in a clinical practice.

In conclusion, pravastatin protected normal intestine and lung tissues from radiation. The radioprotective effect of pravastatin was associated with a reduction in the level of radiation-induced DNA double-strand breaks. The use of pravastatin may therefore increase the therapeutic index for radiotherapy.

\section{Acknowledgements}

The authors appreciate the contribution of Mr. Daisuke Nagata from the Institute of Experimental Animal Sciences, Hyogo College of Medicine (Nishinomiya, Japan). This work was supported by Grant-in-Aid for Young Scientists (B) (grant no. 25861134) Grant-in-Aid for Young Scientists (C) (grant no. $16 \mathrm{~K} 10707)$.

\section{References}

1. Kavanagh BD, Pan CC, Dawson LA, Das SK, Li XA, Ten Haken RK and Miften M: Radiation dose-volume effects in the stomach and small bowel. Int J Radiat Oncol Biol Phys 76 (3 Suppl): S101-S107, 2010.

2. Lalla RV, Bowen J, Barasch A, Elting L, Epstein J, Keefe DM, McGuire DM, Migliorati C, Nicolatou-Galitis O, Peterson DE, et al: MASCC/ISOO clinical practice guidelines for the management of mucositis secondary to cancer therapy. Cancer 120: 1453-1461, 2014.

3. Brizel DM, Wasserman TH, Henke M, Strnad V, Rudat V, Monnier A, Eschwege F, Zhang J, Russell L, Oster W and Sauer R: Phase III randomized trial of amifostine as a radioprotector in head and neck cancer. J Clin Oncol 18: 3339-3345, 2000.

4. Jellema AP, Slotman BJ, Muller MJ, Leemans CR, Smeele LE, Hoekman K, Aaronson NK and Langendijk JA: Radiotherapy alone, versus radiotherapy with amifostine 3 times weekly, versus radiotherapy with amifostine 5 times weekly: A prospective randomized study in squamous cell head and neck cancer. Cancer 107: 544-553, 2006.

5. Nakamura H, Arakawa K, Itakura H, Kitabatake A, Goto Y, Toyota T, Nakaya N, Nishimoto S, Muranaka M, Yamamoto A, et al: Primary prevention of cardiovascular disease with pravastatin in Japan (MEGA Study): A prospective andomized controlled trial. Lancet 368: 1155-1163, 2006.

6. Rosenson RS, Tangney CC and Casey LC: Inhibition of proinflammatory cytokine production by pravastatin. Lancet 353 : 983-984, 1999.

7. Holler V, Buard V, Gaugler MH, Guipaud O, Baudelin C, Sache A, Perez Mdel R, Squiban C, Tamarat R, Milliat F and Benderitter M: Pravastatin limits radiation-induced vascular dysfunction in the skin. J Invest Dermatol 129: 1280-1291, 2009.

8. Haydont V, Bourgier C, Pocard M, Lusinchi A, Aigueperse J, Mathé D, Bourhis J and Vozenin-Brotons MC: Pravastatin Inhibits the Rho/CCN2/extracellular matrix cascade in human fibrosis explants and improves radiation-induced intestinal fibrosis in rats. Clin Cancer Res 13: 5331-5340, 2007.

9. Haydont V, Gilliot O, Rivera S, Bourgier C, François A, Aigueperse J, Bourhis J and Vozenin-Brotons MC: Successful mitigation of delayed intestinal radiation injury using pravastatin is not associated with acute injury improvement or tumor protection. Int J Radiat Oncol Biol Phys 68: 1471-1482, 2007. 
10. Gaugler MH, Vereycken-Holler V, Squiban C, Vandamme M, Vozenin-Brotons MC and Benderitter M: Pravastatin limits endothelial activation after irradiation and decreases the resulting inflammatory and thrombotic responses. Radiat Res 163: 479-487, 2005.

11. Mahmoudi M, Gorenne I, Mercer J, Figg N, Littlewood T and Bennett M: Statins use a novel Nijmegen breakage syndrome-1-dependent pathway to accelerate DNA repair in vascular smooth muscle cells. Circ Res 103: 717-725, 2008.

12. Nübel T, Damrot J, Roos WP, Kaina B and Fritz G: Lovastatin protects human endothelial cells from killing by ionizing radiation without impairing induction and repair of DNA double-strand breaks. Clin Cancer Res 12: 933-939, 2006.

13. Ostrau C, Hülsenbeck J, Herzog M, Schad A, Torzewski M, Lackner KJ and Fritz G: Lovastatin attenuates ionizing radiation-induced normal tissue damage in vivo. Radiother Oncol 92. 492-499, 2009

14. Jenrow KA, Liu J, Brown SL, Kolozsvary A, Lapanowski K and $\mathrm{Kim} \mathrm{JH}$ : Combined atorvastatin and ramipril mitigate radiation-induced impairment of dentate gyrus neurogenesis. J Neurooncol 101: 449-456, 2011.

15. Wedlake LJ, Silia F, Benton B, Lalji A, Thomas K, Dearnaley DP, Blake P, Tait D, Khoo VS and Andreyev HJ: Evaluating the efficacy of statins and ACE-inhibitors in reducing gastrointestinal toxicity in patients receiving radiotherapy for pelvic malignancies. Eur J Cancer 48: 2117-2124, 2012.

16. Withers HR and Elkind MM: Radiosensitivity and fractionation response of crypt cells of mouse jejunum. Radiat Res 38: 598-613, 1969.

17. Tian J, Doi H, Saar M, Santos J, Li X, Peehl DM and Knox SJ: Radioprotection and cell cycle arrest of intestinal epithelial cells by darinaparsin, a tumor radiosensitizer. Int J Radiat Oncol Biol Phys 87: 1179-1185, 2013.

18. Potten CS and Grant HK: The relationship between ionizing radiation-induced apoptosis and stem cells in the small and large intestine. Br J Cancer 78: 993-1003, 1998.

19. Johnston CJ, Hernady E, Reed C, Thurston SW, Finkelstein JN and Williams JP: Early alterations in cytokine expression in adult compared to developing lung in mice after radiation exposure. Radiat Res 173: 522-535, 2010.

20. Cho H, Matsumoto S, Fujita Y, Kuroda A, Menju T, Sonobe M, Kondo N, Torii I, Nakano T and Lara PN, et al: Trametinib plus 4-methylumbelliferone exhibits antitumor effects by ERK blockade and CD44 downregulation and affects PD1 and PD-L1 in malignant pleural mesothelioma. J Thorac Oncol: Nov 17, 2016 (Epub ahead of print)

21. Rotolo JA, Kolesnick R and Fuks Z: Timing of lethality from gastrointestinal syndrome in mice revisited. Int J Radiat Oncol Biol Phys 73: 6-8, 2009.

22. Hauer-Jensen M, Denham JW and Andreyev HJ: Radiation enteropathy-pathogenesis, treatment and prevention. Nat Rev Gastroenterol Hepatol 11: 470-479, 2014.
23. Doi H, Kamikonya N, Takada Y, Fujiwara M, Tsuboi K, Miura H, Inoue H, Tanooka M, Nakamura T, Shikata T, et al: Long-term sequential changes of radiation proctitis and angiopathy in rats. J Radiat Res 53: 217-224, 2012

24. Potten CS: Radiation, the ideal cytotoxic agent for studying the cell biology of tissues such as the small intestine. Radiat Res 161: 123-136, 2004

25. Gomez DR, Hong DS, Allen PK, Welsh JS, Mehran RJ, Tsao AS, Liao Z, Bilton SD, Komaki R and Rice DC: Patterns of failure, toxicity, and survival after extrapleural pneumonectomy and hemithoracic intensity-modulated radiation therapy for malignant pleural mesothelioma. J Thorac Oncol 8: 238-245, 2013

26. Soto DE, Daignault S, Sandler HM and Ray ME: No effect of statins on biochemical outcomes after radiotherapy for localized prostate cancer. Urology 73: 158-162, 2009.

27. Gauthaman K, Manasi N and Bongso A: Statins inhibit the growth of variant human embryonic stem cells and cancer cells in vitro but not normal human embryonic stem cells. Br J Pharmacol 157: 962-973, 2009.

28. Gabryś D, Dörfler A, Yaromina A, Hessel F, Krause M, Oertel R and Baumann M: Effects of lovastatin alone or combined with irradiation on tumor cells in vitro and in vivo. Strahlenther Onkol 184: 48-53, 2008

29. Fritz G, Brachetti C and Kaina B: Lovastatin causes sensitization of HeLa cells to ionizing radiation-induced apoptosis by the abrogation of G2 blockage. Int J Radiat Biol 79: 601-610, 2003.

30. Zaorsky NG, Buyyounouski MK, Li T and Horwitz EM: Aspirin and statin nonuse associated with early biochemical failure after prostate radiation therapy. Int J Radiat Oncol Biol Phys 84: e13-e17, 2012.

31. Larner J, Jane J, Laws E, Packer R, Myers C and Shaffrey M: A phase I-II trial of lovastatin for anaplastic astrocytoma and glioblastoma multiforme. Am J Clin Oncol 21: 579-583, 1998.

32. Konings IR, van der Gaast A, van der Wijk LJ, de Jongh FE, Eskens FA and Sleijfer S: The addition of pravastatin to chemotherapy in advanced gastric carcinoma: A andomized phase II trial. Eur J Cancer 46: 3200-3204, 2010.

33. Kastan MB and Bartek J: Cell-cycle checkpoints and cancer. Nature 432: 316-323, 2004.

34. Koga T, Shimada Y, Kuroda M, Tsujita Y, Hasegawa K and Yamazaki M: Tissue-selective inhibition of cholesterol synthesis in vivo by pravastatin sodium, a 3-hydroxy-3-methylglutaryl coenzyme A reductase inhibitor. Biochim Biophys Acta 1045: $115-120,1990$.

35. Alberton M, Wu P, Druyts E, Briel M and Mills EJ: Adverse events associated with individual statin treatments for cardiovascular disease: An indirect comparison meta-analysis. QJM 105: 145-157, 2012. 